\title{
EVENTOS TECTÔNICOS RECORRENTES IMPRESSOS NO ARCABOUÇO ESTRATIGRÁFICO DO GRUPO ITARARÉ NA REGIÃO DE VILA VELHA, ESTADO DO PARANÁ
}

\author{
RECURRENCE OF TECTONIC EVENTS OVERPRINT IN THE \\ CARBONIFEROUS VILA VELHA SANDSTONES OF THE ITARARÉ \\ GROUP, PARANÁ BASIN, SOUTH BRAZIL
}

\author{
Barbara TRZASKOS 1,2 \\ Fernando Farias VESELY1,2 \\ Sidnei Pires ROSTIROLLA ${ }^{2}$
}

\begin{abstract}
RESUMO
O presente trabalho avalia o controle tectônico na deposição e deformação do intervalo basal do Grupo Itararé no sudeste do Estado do Paraná e sua influência na anisotropia de reservatórios análogos. A partir da análise estrutural do arenito Vila Velha, a observação das relações espaciais entre a conformação dos estratos e as estruturas descritas e o mapeamento geológico de detalhe, propõe-se um modelo de evolução tectono-sedimentar para a área. O Grupo Itararé foi depositado em contexto glacial, glácio-marinho e costeiro, tendo sido afetado por vários eventos tectônicos que influenciaram a sedimentação e deformaram a seção sedimentar. A descrição do arcabouço estrutural/estratigráfico sugere uma história tectônica complexa, do Carbonífero ao Eocretáceo, com estruturas tectonicamente ativas durante a deposição e a sua reativação em eventos tectônicos posteriores. A natureza da sedimentação e a deformação tectônica superimposta em múltiplos eventos imprimiram no arenito intensa anisotropia, com diferentes escalas de heterogeneidades estruturais e estratigráficas que limitam unidades de fluxo e controlam a circulação de fluidos no meio poroso.

Palavras-chave: Grupo Itararé; arenito Vila Velha; análise estrutural; tectônica e sedimentação; reservatório análogo.
\end{abstract}

1 UFPR/Pós-Graduação em Geologia.

2 UFPR/Laboratório de Análise de Bacias e Petrofísica. 


\title{
ABSTRACT
}

\begin{abstract}
This paper describes the tectonic control on the depositional and post depositional evolution of the late Carboniferous glacial Itararé Group in the eastern flank of the Paraná Basin, southeast Paraná State. Emphasis was given on the structural and stratigraphic organization of the Vila Velha sandstone, an outcrop analogue to subsurface reservoirs in the Ponta Grossa - Itararé petroleum system. The study was based on satellite image and digital elevation model analysis, aerial photograph interpretations (1:25.000 and 1:10.000), detailed vertical stratigraphic profiles, descriptive, kinematic and dynamic analysis of deformational structures and geological mapping. The results suggest a series of tectonic events related to Phanerozoic evolution of the South American Platform that can be observed in the Vila Velha sandstone. In the studied area, the Itararé Group was deposited unconformably on a Devonian basement affected by tectonism triggered by the EoHercynian orogeny during Late Devonian to Late Carboniferous times. Distribution of the lowermost glacial facies of the Itararé Group and its spatial relationship with major tectonic features suggest tectonic control during the first depositional phase in the Late Carboniferous. The second depositional phase was marked by deposition in marine, glaciomarine and shoreline environments due to deglaciation. This episode produced a $100 \mathrm{~m}$ thick and highly heterogeneous sand-rich succession (Vila Velha sandstone). Structural analysis showed that these sandstones were affected by at least three brittle deformational events, which appear as fracture systems and fault zones visible on remote sensing images and direct outcrop observation. The first deformation event generated north-northeast fracturing and northeast sinistral strike-slip faulting, exemplified by the Fortaleza Fault, probably related to Fini-Hercynian intraplate stress propagation induced by the Permian La Ventana-Cabo orogeny recorded in the Sierras Australes of Buenos Aires. The second event is recorded by northwest fractures and normal faults clearly related to the Early Cretaceous extensional and magmatic event due to the South-Atlantic rifting. This event produced the uplift of the Ponta Grossa Arch and the development of regional northwest structures that cross almost the entire basin, like the Rio Alonzo lineament. Patterns of sedimentation and superimposed tectonic deformations observed in the Vila Velha sandstone provide a stratigraphic/structural anisotropy that control flow units and fluid circulation within the porous media.
\end{abstract} analogue.

Key-words: Itararé Group; Vila Velha sandstone; structural analysis; tectonic evolution; reservoir

\section{INTRODUÇÃO}

No flanco sul do Arco de Ponta Grossa ocorrem boas exposições de rochas do Carbonífero Superior da Bacia do Paraná, pertencentes ao Grupo Itararé. Dentro da sucessão sedimentar presente, destacam-se espessas seções arenosas da parte inferior da Formação Campo Mourão, aflorantes na região sudeste do Estado do Paraná (figura 1) e denominados de arenitos Lapa e Vila Velha (França et al. 1996).

A sucessão é, grosso modo, cronocorrelata ao intervalo produtor de gás na Bacia do Paraná (Sistema Petrolífero Ponta Grossa - Itararé), sendo os arenitos considerados análogos aos reservatórios explorados em profundidade. As exposições são muitas vezes contínuas tanto na horizontal quanto verticalmente e permitem observar heterogeneidades estruturais e estratigráficas que não podem ser constatadas com métodos indiretos em subsuperfície.

Os afloramentos típicos do arenito Vila Velha situam-se $30 \mathrm{~km}$ a sudeste da cidade de Ponta Grossa, estendendo-se por uma área de aproximadamente 100 $\mathrm{km}^{2}$ no Parque Estadual de Vila Velha e arredores (figuras 2 e 3). O arenito destaca-se na topografia como platôs isolados, limitados por escarpas pronunciadas com dezenas de metros de altura. À distância observa-se que a faixa de exposição dos arenitos do parque apresentase levemente arqueada, com eixo orientado segundo norte-sul (figura 2). Por causa do excelente grau de preservação das fácies sedimentares e do ótimo acervo de estruturas deformacionais relacionadas a zonas de falha regionais, a área oferece a oportunidade de analisar aspectos da tectônica formadora e modificadora da seção sedimentar.

O presente trabalho tem como escopo analisar o intervalo basal do Grupo Itararé aflorante na área de Vila Velha, a partir da integração entre dados estruturais e estratigráficos, para interpretar sua dinâmica tectonosedimentar. Para isso, foram estabelecidos os seguintes objetivos: 1. detalhamento estratigráfico do intervalo estudado e sua representação em mapa a partir de análise fotogeológica (1:25.000); 2. identificação e descrição das estruturas deformacionais em campo e sensores remotos; 3. reconhecimento de indicadores cinemáticos disponíveis e análise dinâmica; 4. determinação dos eventos deformacionais e suas relações com o empilhamento estratigráfico; 5 . interpretação da evolução tectonosedimentar integrada ao contexto geológico regional. 


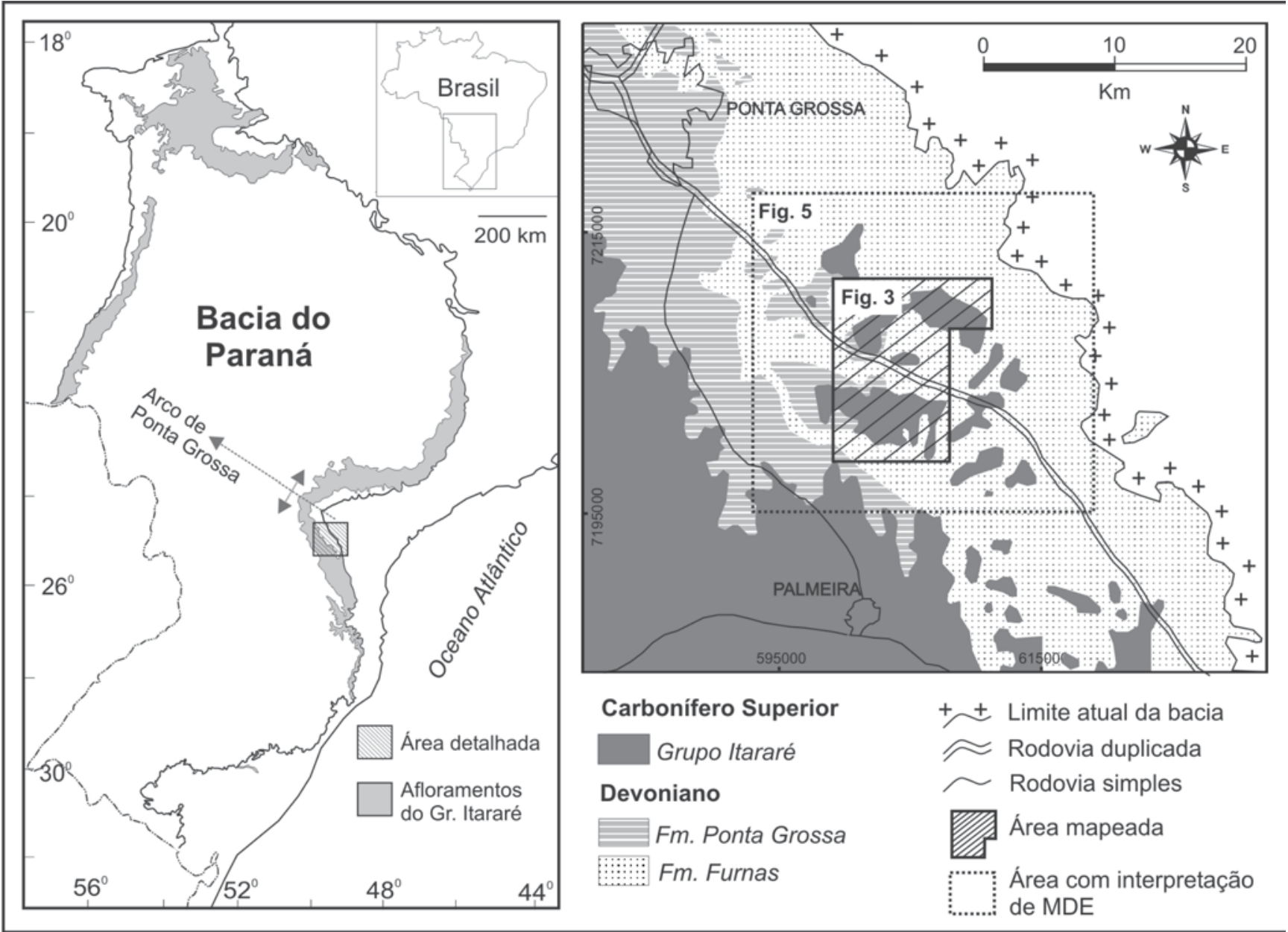

Figura 1 - Localização e esboço geológico da área estudada no sudeste do Estado do Paraná.

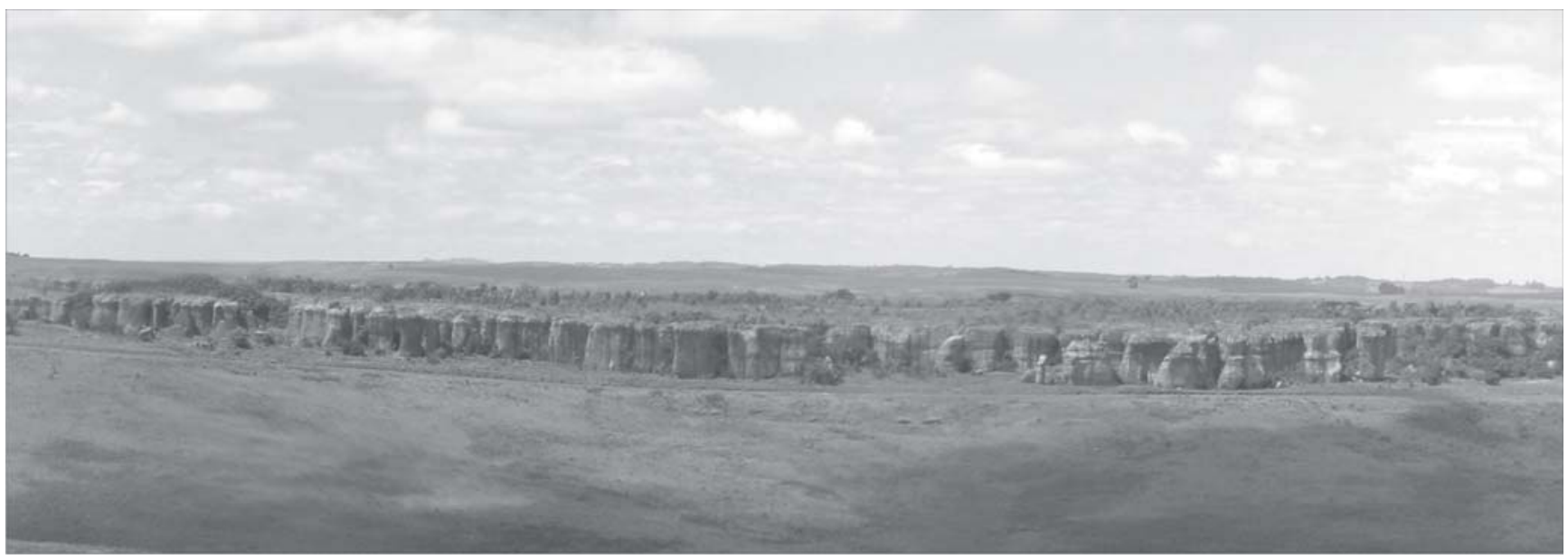

Figura 2 - Foto panorâmica das formações rochosas do Parque Estadual de Vila Velha, expondo arenitos tabulares levemente arqueados e secionados por fraturas subverticais. Vista de norte para sul. 
Como produto da análise fotogeológica foi gerado um mapa lito-estrutural do arenito Vila Velha, com a distribuição das unidades estratigráficas mapeáveis na escala 1:25.000 e dos principais elementos estruturais reconhecidos (figura 3). Paralelamente, foi possível identificar diferentes tipos e escalas de heterogeneidades existentes nos arenitos, bem como propor um modelo genético para um dos intervalos mais prospectivos da Bacia do Paraná. Resultados precursores sobre o tema foram publicados em Rostirolla et al. (2002), TrzaskosLipski et al. (2003) e Vesely et al. (2003a,b).

\section{CONTEXTO ESTRATIGRÁFICO}

Segundo a classificação litoestratigráfica de França \& Potter (1991), o Grupo Itararé comporta três grandes ciclos com argilosidade crescente para o topo, denominados de formações Lagoa Azul, Campo Mourão e Taciba. Essas três unidades são mapeáveis em subsuperfície e são, grosso modo, correlatas às formações Campo do Tenente, Mafra e Rio do Sul, mapeadas na borda leste catarinense da bacia por Schneider et al. (1974).

$\mathrm{Na}$ área estudada, o Grupo Itararé repousa em discordância erosiva de baixo ângulo sobre a seqüência devoniana da Bacia do Paraná (Assine 1996), ora sobre a Formação Furnas, ora sobre a Formação Ponta Grossa, sugerindo irregularidade da superfície discordante.

A seção basal do Grupo Itararé na área é constituída por diamictitos e folhelhos rítmicos de cor marrom-avermelhada com algumas intercalações arenosas, depositados em contexto subglacial a gláciomarinho. De acordo com datações e correlações apresentadas por França et al. (1996), essa associação de fácies pertence à metade superior da Formação Lagoa Azul (Membro Tarabaí), que tem composição essencialmente lamítica e contém palinomorfos do Carbonífero Superior (andar Westfaliano). Essa formação apresenta grande variação lateral de espessura na área, tanto por causa da existência de um paleorelevo esculpido sobre o embasamento devoniano quanto pela erosão que precedeu a deposição dos estratos mais jovens. A espessura máxima observada é de 25 metros na porção sul da área. Para norte, a Formação Lagoa Azul sofre acunhamento até desaparecer por completo.

Os sedimentos finos da Formação Lagoa Azul são superpostos mediante discordância erosiva por uma espessa sucessão de arenitos, localmente com conglomerados basais. Essa sucessão alcança espessura de aproximadamente 100 metros e corresponde ao que foi denominado de arenito Vila Velha por Maack (1946). Equivale em subsuperfície à sucessão arenosa presente no terço basal da Formação Campo Mourão (França et al. 1996).

Quatro unidades litoestratigráficas foram identificadas no arenito Vila Velha, denominadas da base para o topo de A, B, C e D e mapeáveis na escala 1:25.000 com auxílio de fotointerpretação (figura 3 ). O empilhamento e as sucessões verticais de fácies de cada unidade foram descritos e interpretados por Vesely et al. (2003a), a partir do levantamento e correlação de perfis estratigráficos verticais (figura 4).

A unidade A compreende uma associação de conglomerados e arenitos mal selecionados depositados em leques proglaciais subaquosos (outwash). O topo dessa unidade é retrogradante e culmina com uma sucessão glácio-marinha argilosa composta por folhelhos, ritmitos e diamictitos (unidade B). O conjunto formado pelas unidades $C$ e $D$, assentado em contato erosivo sobre a anterior, compreende uma espessa sucessão arenosa de turbiditos hiperpicnais interdigitados com fácies de barras de desembocadura e depósitos de praia no topo. Toda a sucessão equivalente ao arenito Vila Velha representa um ciclo transgressivo-regressivo de $3^{\mathrm{a}}$ ordem na base da Formação Campo Mourão, conforme o modelo de Vesely \& Assine (2004) e Vesely et al. (2003a).

\section{ARCABOUÇO ESTRUTURAL}

\section{Análise descritiva}

Para a análise estrutural da área de Vila Velha, foi previamente delimitada uma área mais abrangente representativa do contexto tectônico no flanco sul do Arco de Ponta Grossa (figura 1). Essa área foi destinada ao traçado e interpretação de lineamentos a partir de sensores remotos (Modelo Digital de Elevação - MDE e Imagem LANDSAT), para determinar a influência de feições regionais sob a área mapeada e a expressão morfológica das estruturas (figuras 5 e 6 ).

A seção sedimentar paleozóica exposta na área é marcada por uma deformação rúptil que compreende três famílias principais de fraturas subverticais, cuja expressão em planta varia de acordo com a escala de observação. A primeira família, de direção N50W, apresenta-se normalmente como um feixe de lineamentos retilíneos e alongados, podendo ser visualizados tanto sobre as rochas da Formação Furnas quanto sobre o embasamento cristalino, sendo ainda responsáveis localmente pelo contato escarpado entre as duas unidades.

Essa família é facilmente reconhecida em imagem de satélite e no Modelo Digital de Elevação (MDE), estando bem marcada na porção nordeste da área (figura 5). Exemplo de sua expressão sobre as rochas do Grupo 


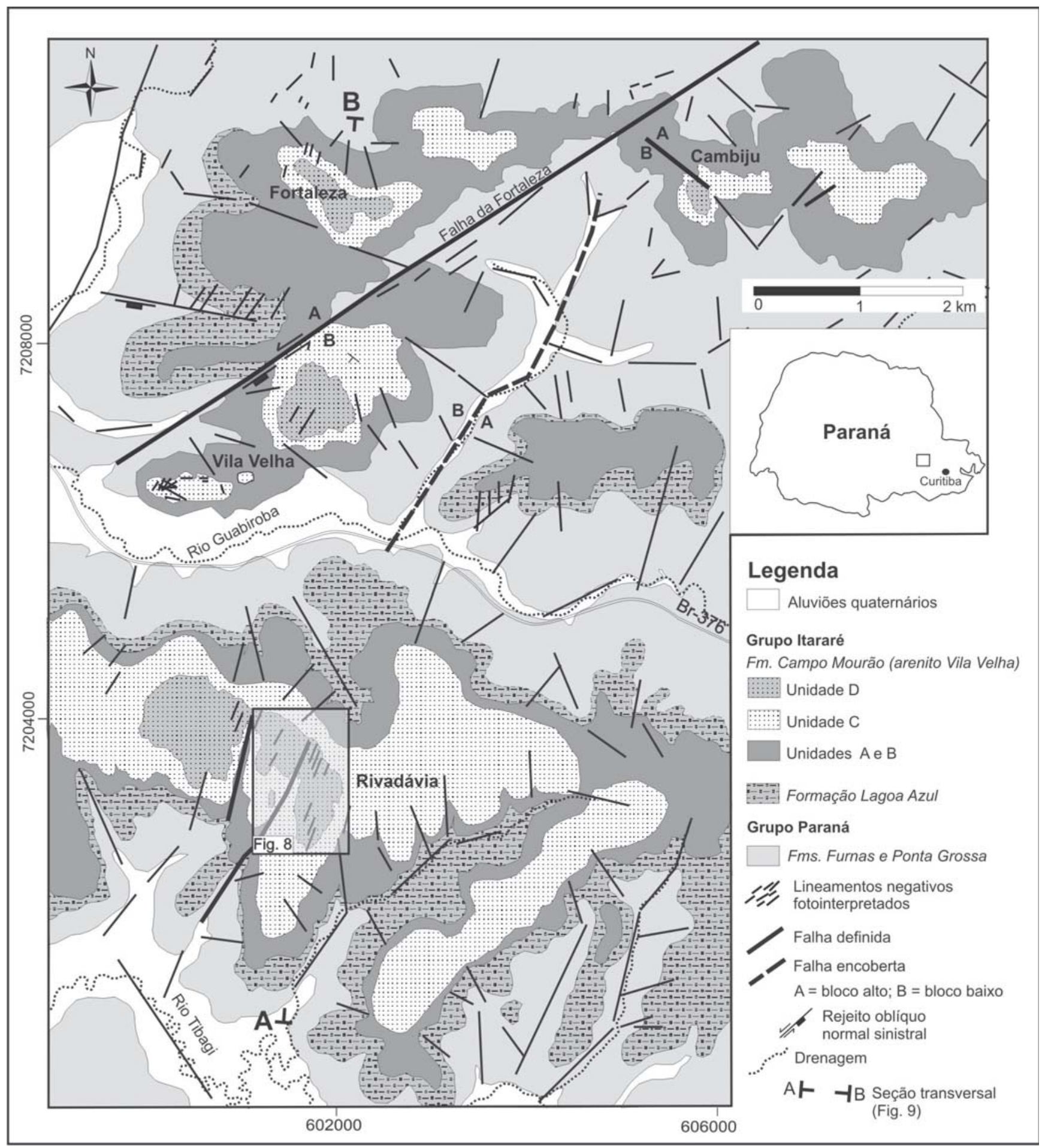

Figura 3 - Mapa geológico lito-estrutural do Grupo Itararé na área de Vila Velha. 


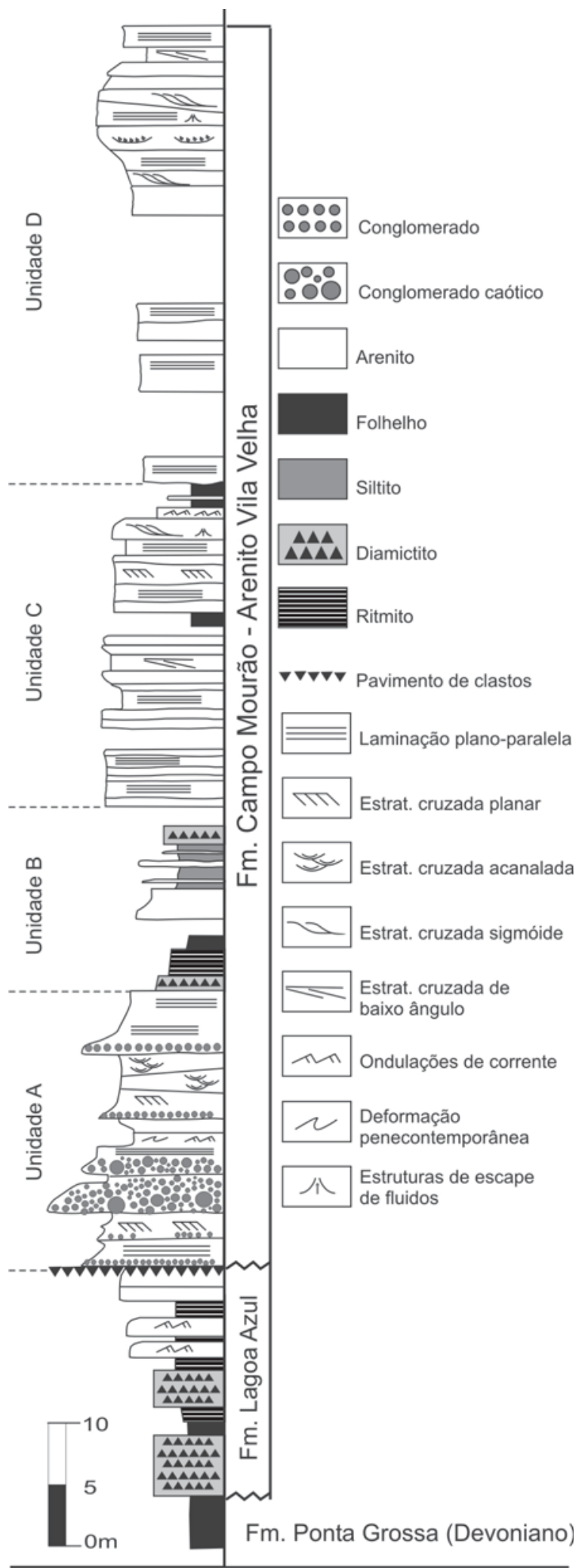

Figura 4 - Perfil vertical composto, ilustrando o empilhamento estratigráfico do Grupo Itararé na área de Vila Velha (modificado de Vesely et al. 2003a). 

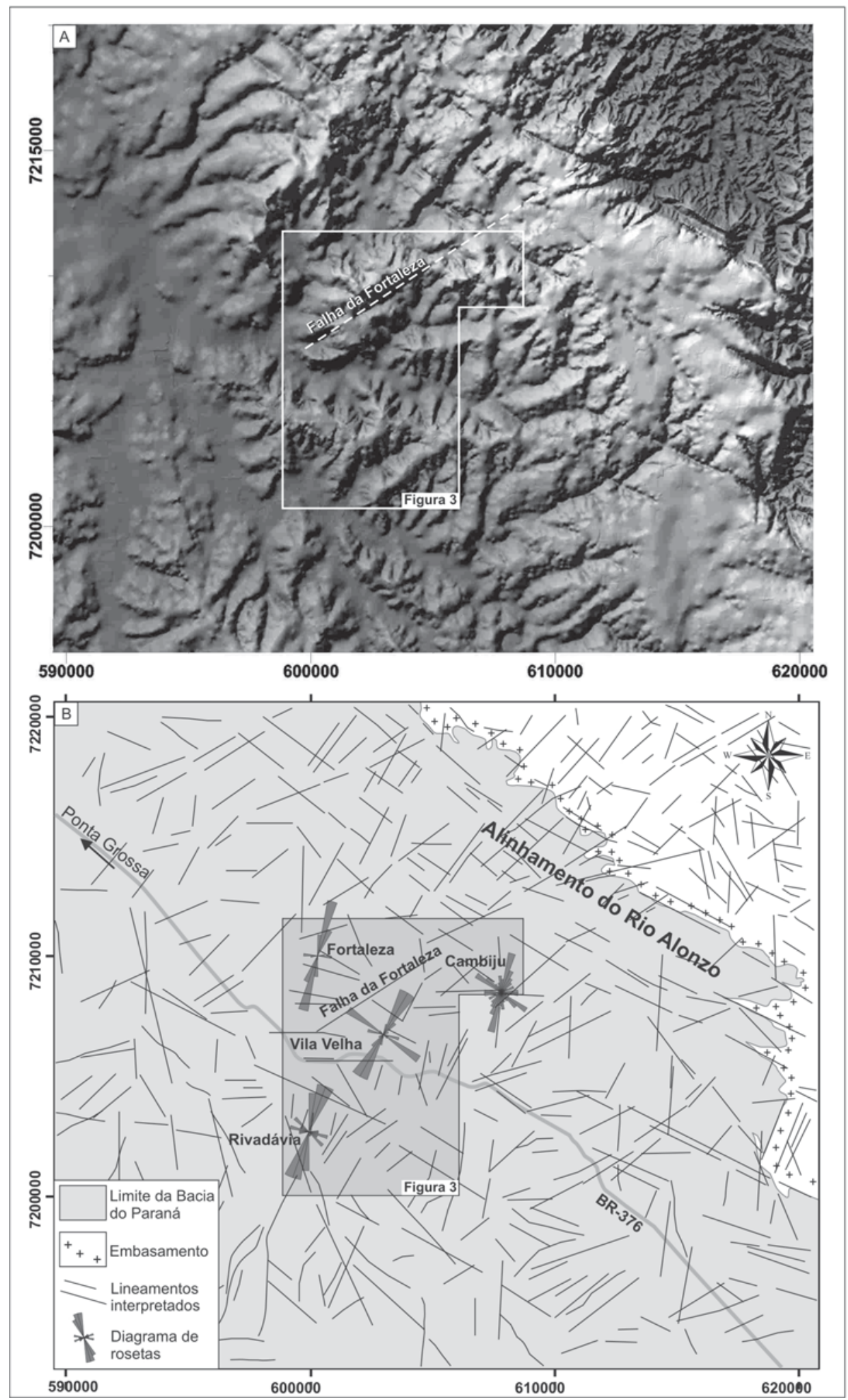

Figura 5 - a) Modelo digital de elevação (MDE) com iluminação de NW; b) mapa de lineamentos extraídos de imagem de satélite e MDE, com diagramas em rosetas das atitudes de fraturas obtidas em campo. Para localização vide figura 1. 


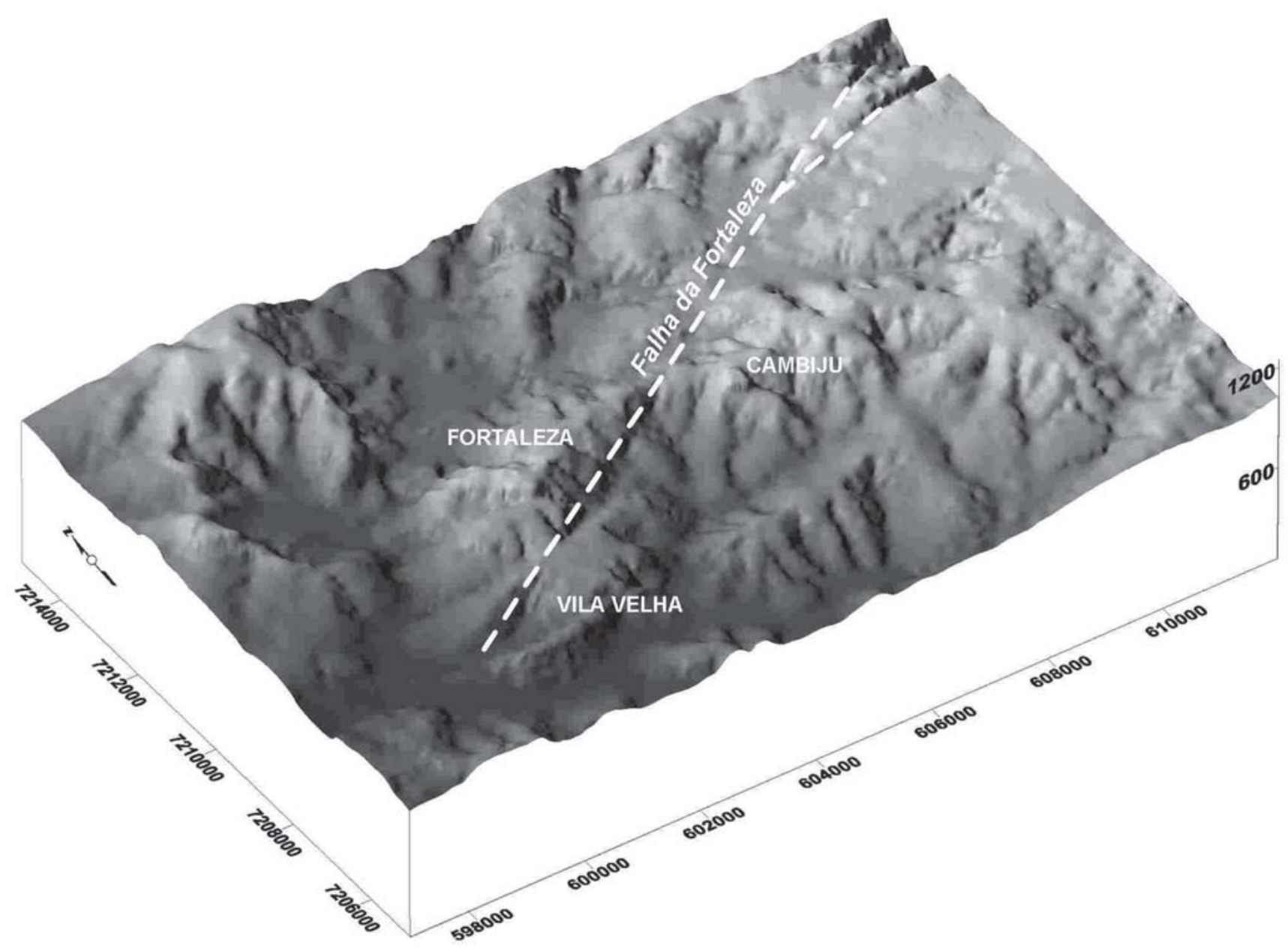

Figura 6 - Modelo tridimensional do relevo, ilustrando a feição morfoestrutural da Falha da Fortaleza.

Itararé ocorre na área da Fazenda Cambiju (figura 3), onde foi observada uma falha normal com rejeito métrico (figura 7a). No contexto regional, essa direção noroeste pode ser associada ao Alinhamento do Rio Alonzo, definido como uma proeminente anomalia magnética linear paralela ao eixo do Arco de Ponta Grossa (Vieira 1973, Ferreira 1982, Zalán et al. 1987).

A segunda família de fraturas, de direção N10-20E, apresenta-se bem marcada em fotografias aéreas (1:25.000 e 1:10.000) e em afloramentos do Grupo Itararé, englobando as áreas da Fazenda Rivadávia, Fazenda Cambiju e nos arenitos do Parque Estadual de Vila Velha (figura 3). Este sistema de fraturas apresenta espaçamento variando de largo a muito largo $(0,2-2 \mathrm{~m})$, geometria variando de ondulada a anastomosada (figuras 7b e 7c) e rugosidade moderada. Comumente podem ser observados padrões en échelon, com escalonamento dos planos de fraturas. Alguns planos exibem pequenas zonas de cisalhamento, classificadas como bandas de deformação segundo a definição de Aydin (1978), apresentando características de deformação inter e intragranular, concentrada em estreitas faixas e com rejeitos de decímetros a poucos metros. As bandas de deformação podem ser facilmente reconhecidas em campo por se apresentarem como ressaltos no relevo por causa do atual preenchimento por hidróxidos de ferro (figuras 7b e 7c). A disposição geral dos sistemas de falhas e fraturas subverticais atribui à área a configuração de pequenos horsts e grabens, com leves basculamentos das camadas e pequena rotação entre os blocos (Rostirolla et al. 2002, Trzaskos-Lipski \& Rostirolla 2005).

A terceira família de fraturas tem direção média N40E e está representada por lineamentos retilíneos, visíveis no MDE e em imagens de satélite (figura 5). Na 
área mapeada, essa direção manifesta-se como um lineamento principal presente no norte da área (figura 3), que atravessa o arenito Vila Velha na área do parque estadual. Essa estrutura foi aqui denominada de Falha da Fortaleza, pois seus melhores afloramentos foram descritos na localidade de Fortaleza, situada no limite norte do parque. Em termos de expressão morfológica e continuidade, trata-se da feição estrutural mais importante reconhecida na área de Vila Velha (figuras 5 e 6).

Outras direções de lineamentos podem ser indicadas a partir da análise de sensores remotos, tais como NNW e E-W (figura 5). No entanto, trata-se de sistemas de fraturas subordinados e, por não terem sido identificados na área mapeada, não foram analisados em detalhe nem incorporados na interpretação da evolução tectônica do arenito Vila Velha.

\section{Análises cinemática e dinâmica}

Foram observados planos de falha orientados segundo a direção N10-20E, cuja movimentação é evidenciada por lineações e degraus (steps) (figura 7d) ou escalonamento dos planos de fraturas. O levantamento de indicadores cinemáticos, cujas melhores exposições são observadas na Fazenda Rivadávia, mostrou que as lineações apresentam rake médio de $18^{\circ}$, o que determina movimentação oblíqua sinistral-normal (figura 7d). A partir das atitudes de 19 planos estriados de direção NNE, descritos ao longo da Fazenda Rivadávia (figura 8), foi realizada a análise dinâmica baseada no critério de ruptura de Mohr-Coulomb, que indica o posicionamento do tensor máximo $\mathrm{s}_{1}$ suborizontal segundo a direção $\mathrm{N} 16 \mathrm{~W}$, o tensor intermediário $\mathrm{s}_{2}$ subvertical e o tensor mínimo $\mathrm{s}_{3}$ aproximadamente E-W (figura 9). A associação entre as informações obtidas em campo e os paleotensores calculados sugere uma deformação distensional, com movimentação direcional oblíqua transtrativa. Trabalhos de análise microestrutural realizados na área (TrzaskosLipski et al. 2003, Trzaskos-Lipski \& Rostirolla 2005) indicam que esse sistema de fraturas é marcado por microfraturas de tração, com rompimento intragranular e com pouco cisalhamento associado.

O sistema NW apresenta-se mais evidente no extremo nordeste da área e sua expressão mais importante ocorre na região da Fazenda Cambiju como um plano de falha de direção N45W de cinemática normal, definida pelo deslocamento relativo entre os blocos (figura 7a). A Falha da Fortaleza apresenta movimentação obliqua normal-sinistral, conforme demonstrado por indicadores cinemáticos e corroborado pela disposição relativa das unidades estratigráficas vista em perfis verticais e seções transversais (figura 10). Além disso, a descrição dos afloramentos em ambos os lados da falha mostra relações de contato distintas entre o Grupo Itararé e o substrato devoniano, sugerindo uma movimentação ao longo da falha antes da deposição do Grupo Itararé. O arcabouço geológico atual indica deslocamento relativo entre os estratos da Formação Campo Mourão, com bloco baixo a sudeste e bloco alto a noroeste e rejeito aproximado de $120 \mathrm{~m}$ (figura 10).

\section{EVOLUÇÃO TECTONO-SEDIMENTAR}

A análise minuciosa do arcabouço estrutural e do empilhamento estratigráfico do Grupo Itararé na área de Vila Velha e sua representação em mapa permitiram identificar diferentes eventos tectônicos que influenciaram a sedimentação e deformaram a seção neopaleozóica. Relacionando os processos sedimentares e deformacionais, foi possível estabelecer a sucessão cronológica dos eventos e estabelecer correlações com episódios tectônicos regionais descritos em trabalhos anteriores.

O contato entre o Grupo Itararé e a seqüência devoniana da Bacia do Paraná é dado por uma discordância regional, denominada de discordância PréPensilvaniano (Soares 1991). A angularidade da superfície discordante indica basculamento tectônico generalizado da superfície pré-Itararé para noroeste, com a erosão atingindo níveis estratigráficos cada vez mais inferiores no sentido sudeste, fato anteriormente já evidenciado por Assine (1996). Outra constatação é a erosão diferencial no topo do Grupo Paraná nos blocos alto e baixo da Falha da Fortaleza, que sugere movimentação ao longo dessa estrutura antes da deposição do Grupo Itararé, com erosão mais pronunciada no bloco alto a noroeste. Por causa da escassez de afloramentos, pequena espessura da Formação Ponta Grossa e ausência de quebras de relevo bem marcadas, não foi possível subdividir as unidades do Grupo Paraná em mapa. Contudo, levantamentos de campo mostram que a noroeste da Falha da Fortaleza o Grupo Itararé repousa em discordância sobre arenitos da Formação Furnas, enquanto a sudeste da falha o contato é dado com folhelhos da Formação Ponta Grossa. Aparentemente, a Falha da Fortaleza exerce influência ainda na distribuição espacial da Formação Lagoa Azul (figura 3). Dessa forma, a atividade tectônica pode ter se prolongado até o início da deposição do Grupo Itararé no Westfaliano, controlando depocentros locais. Essa interpretação corrobora o modelo regional de França \& Potter (1988), que admite a compartimentação da Formação Lagoa Azul em sistemas de horsts e grabens.

A discordância Pré-Pensilvaniano é reconhecida em diversas bacias do Gondwana e o hiato envolvido pode 

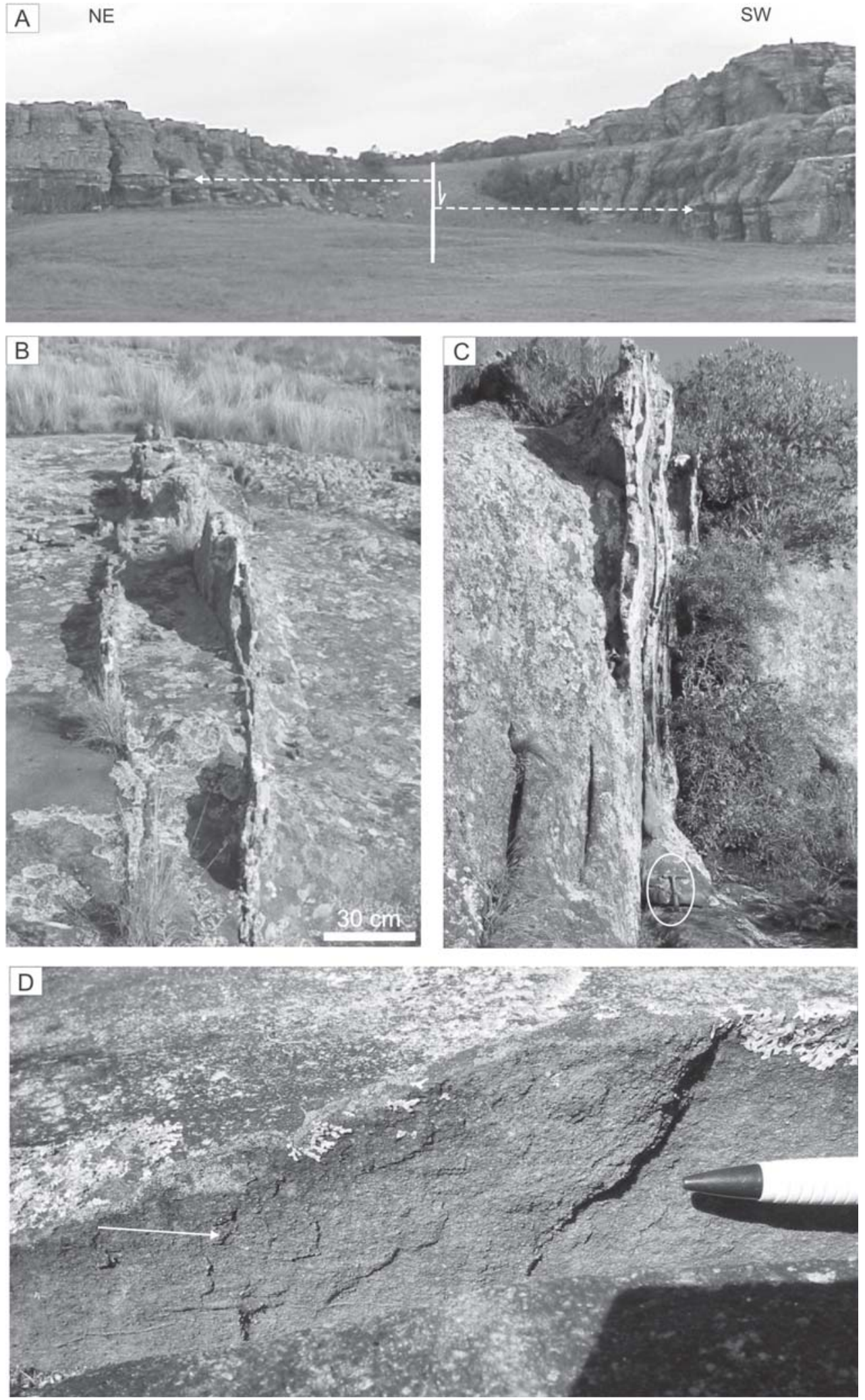

Figura 7 - Fotografias das estruturas rúpteis observadas em campo: a) falha normal observada na Fazenda Cambiju, direção aproximada $\mathrm{N} 45^{\circ} \mathrm{W}$ b) banda de deformação de direção $\mathrm{N} 12 \mathrm{E}$ e geometria anastomosada; c) banda de deformação de direção N10E, subvertical; d) Lineação $\left(016 / 15^{\circ}\right)$ em plano de falha $\left(104 / 84^{\circ}\right)$ com steps indicando cinemática sinistral. 


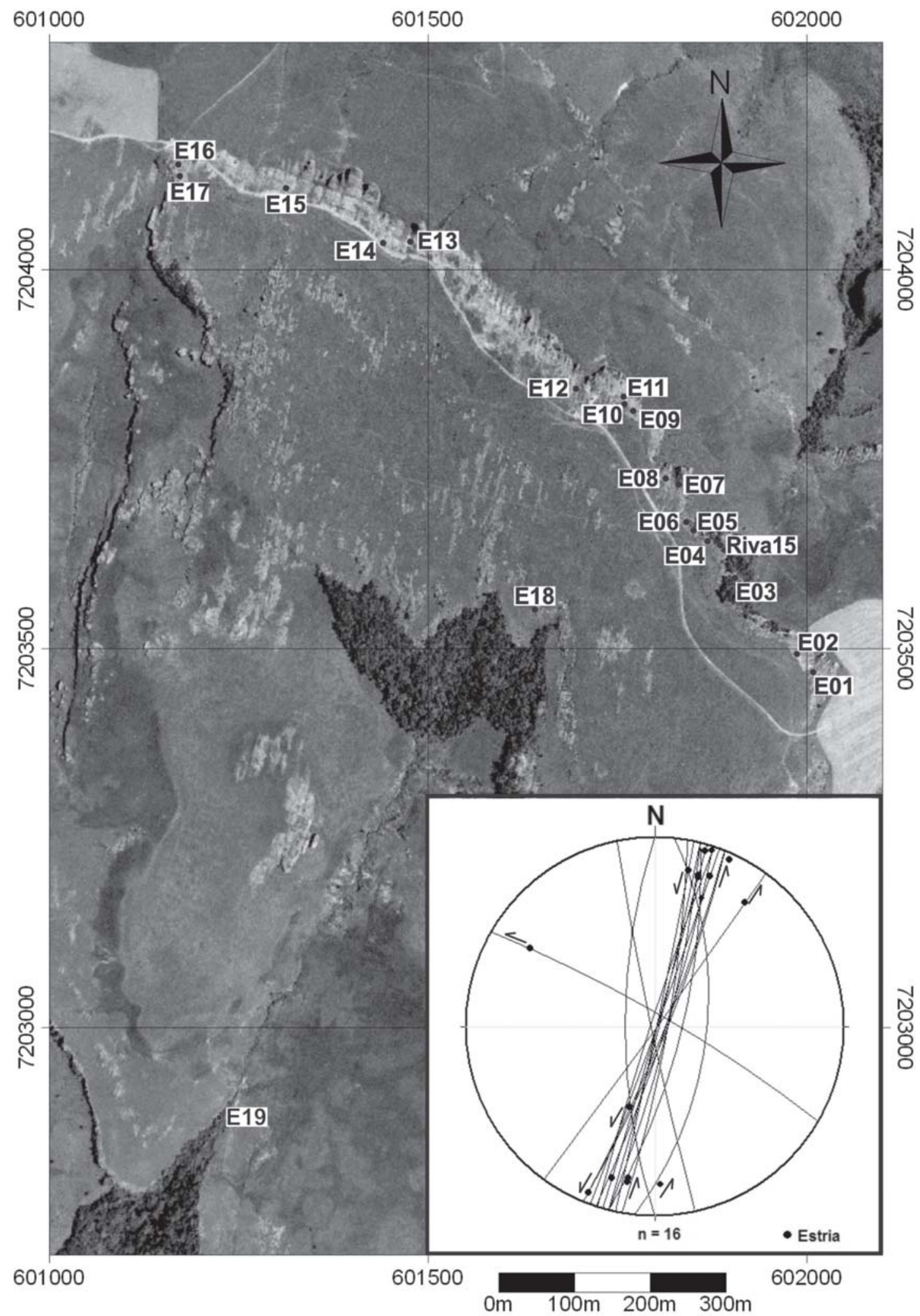

Figura 8 - Fotografia aérea da Fazenda Rivadávia com a localização dos planos estriados utilizados na análise dinâmica e diagrama estereográfico representativo dos planos, estrias e indicadores cinemáticos (localização na figura 3). 

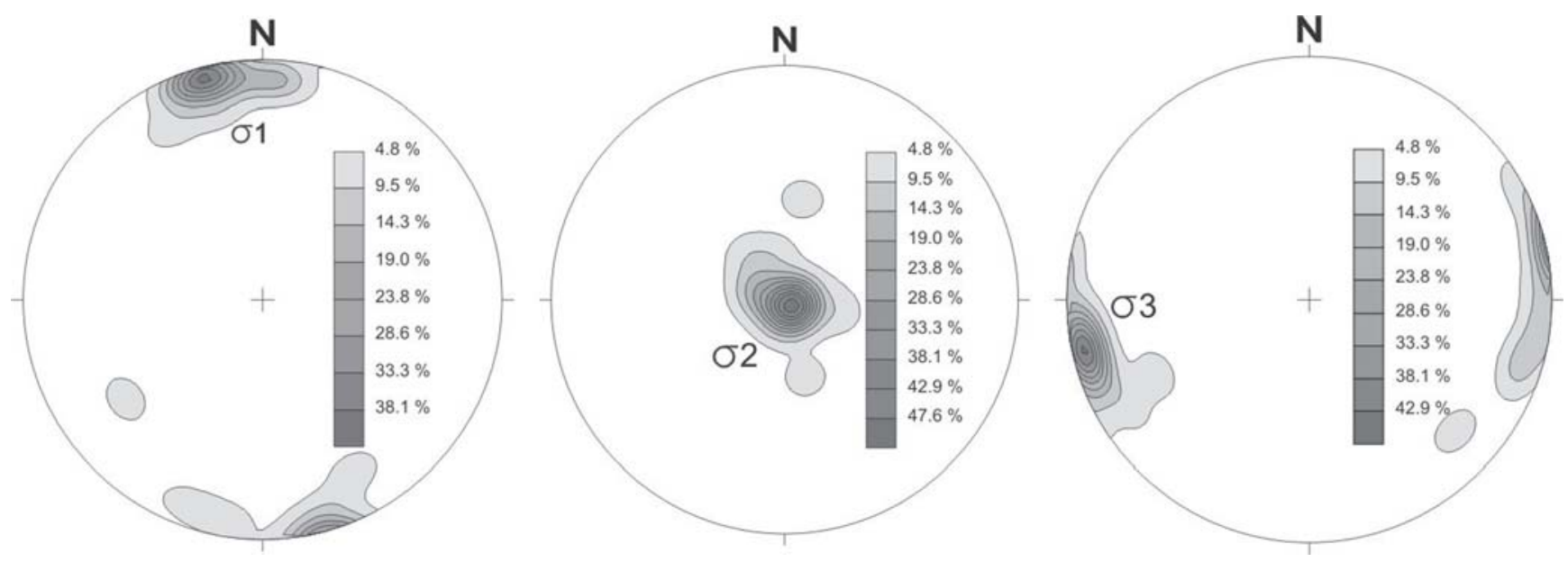

Figura 9 - Diagramas estereográficos das paleotensões responsáveis pela deformação direcional transtrativa, calculada para planos estriados da Fazenda Rivadávia. Número de medidas $=19$.

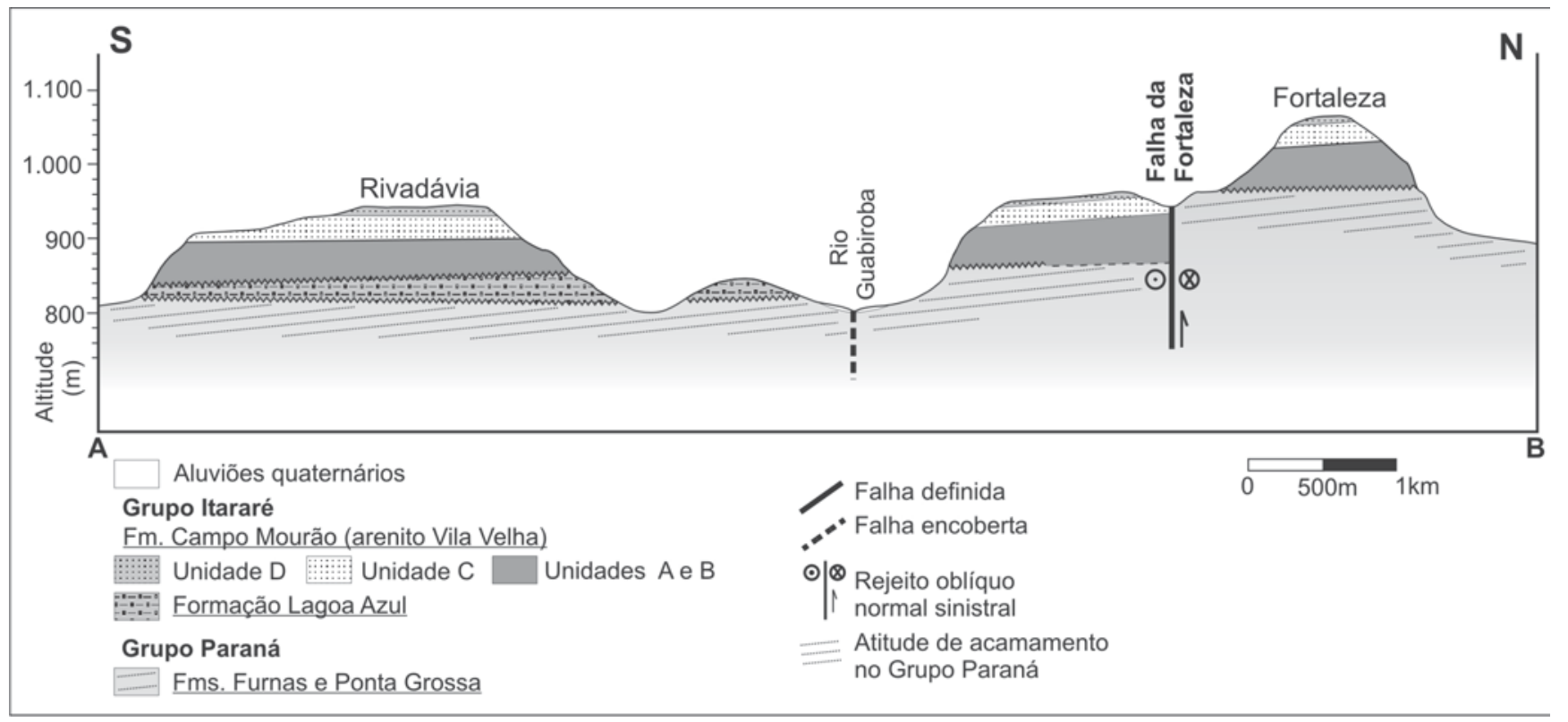

Figura 10 - Seção geológica transversal ilustrando o arcabouço estutural/estratigráfico na área de Vila Velha. Para localização vide figura 3. 
variar de 20 a 90 Ma (López-Gamundí \& Rossello 1993). Segundo os mesmos autores, sua gênese pode ser atribuída a soerguimentos tectônicos influenciados pela orogenia Eo-herciniana. É sugestivo então que o basculamento da superfície pré-Itararé e a movimentação na Falha da Fortaleza sejam testemunhas desse evento tectônico na área estudada. Além disso, outros lineamentos nordeste importantes no sudeste do Paraná, como Rio Tibagi e Lancinha, podem também ter estado ativos durante o intervalo Neodevoniano-Neocarbonífero.

A segunda fase de sedimentação do Grupo Itararé na área compreende os depósitos proglaciais subaquosos da Formação Campo Mourão (arenito Vila Velha), que assentam em discordância erosiva sobre a Formação Lagoa Azul. A deposição dos arenitos ocorreu durante evento de deglaciação que sucedeu a fase de avanço glacial na bacia (Vesely et al. 2003). O gelo e os fluxos de água de degelo geraram erosão pronunciada tanto dos sedimentos glaciais da Formação Lagoa Azul quanto do substrato devoniano. Com isso, a Formação Lagoa Azul foi totalmente erodida em algumas áreas, em que a deposição do arenito Vila Velha ocorreu diretamente sobre as formações Furnas e Ponta Grossa. Sugere-se que a descontinuidade lateral da Formação Lagoa Azul, por erosão diferencial no topo, possa ser atribuída à persistência da movimentação tectônica, refletindo no desenvolvimento de um paleorelevo sobre esses sedimentos e favorecendo a gênese de canais na base da Formação Campo Mourão. Já na opinião de França et al. (1996), a incisão desses canais deve-se provavelmente ao soerguimento da litosfera por reajuste glácio-isostático por causa da fase anterior de deglaciação. Segundo os autores, o soerguimento promoveu exposição subaérea e oxidação das fácies do topo da Formação Lagoa Azul, haja vista sua coloração avermelhada até mesmo em testemunhos de poços. Dados complementares são necessários para confirmar uma ou outra hipótese.

A evolução geológica pós-carbonífera da área estudada foi marcada por eventos de deformação rúptil que afetaram as rochas do Grupo Itararé e cujos registros podem ser verificados no arenito Vila Velha. O arcabouço estrutural atual indica que a área foi afetada por uma tectônica modificadora responsável pela configuração atual das unidades mapeadas. A análise do arcabouço geológico evidencia que a Falha da Fortaleza apresenta natureza recorrente e que foi reativada após a consolidação da Formação Campo Mourão (figura 10).

O primeiro evento deformador das rochas permocarboníferas causou movimentação essencialmente transcorrente sinistral em falhas de direção NE e foi responsável ainda pela nucleação de feições lineares de direção N10-20E, facilmente reconhecidas em fotografias aéreas na região de Vila Velha. Essas zonas de falha de direção nordeste têm sido relacionadas à reativação de estruturas herdadas do embasamento da bacia (p. ex. Rostirolla et al. 2000, Riccomini et al. 2005), que representam as principais descontinuidades formadas durante eventos tectônicos pré-cambrianos. A determinação da idade desse evento tectônico torna-se difícil por causa da ausência de relações deformacionais esclarecedoras. Relações indiretas, como a ausência de indicadores deformacionais de direção NE em diques mesozóicos, sugerem que a deformação ocorreu durante um evento anterior ao Cretáceo.

Trabalhos com enfoque tectônico já realizados na bacia relacionam a movimentação das falhas nordeste à propagação do campo de tensões compressionais intraplaca durante a orogenia La Ventana (Permiano), ocorrida no limite sul da Placa Sul-Americana (Milani 1997, Tankard et al. 1996, Rostirolla et al. 2003). A propagação de esforços de sul para norte teria causado a reativação fanerozóica de estruturas antigas do embasamento, tais como a Zona de Falha da Jacutinga (Soares et al. 1996), Zona de Falha da Lancinha e Zona de Falha do Perimbó (Rostirolla et al. 2003). Nesse quadro, sugere-se que a reativação transcorrente sinistral da Falha da Fortaleza ocorreu provavelmente no Permiano.

O segundo evento deformacional pós-Campo Mourão que atingiu a área foi responsável pela nucleação do sistema de lineamentos retilíneos e alongados de direção N55W, que seccionam a porção nordeste da área. Este evento, relacionado ao soerguimento termal e formação do Arco de Ponta Grossa durante o Eocretáceo, foi responsável não só pelo vulcanismo na Bacia do Paraná, mas também por falhamentos distensionais e geração de fraturas NW, como observado na Fazenda Cambiju (figura 7a).

\section{IMPLICAÇÕES PARA O MODELO EXPLORATÓRIO}

$\mathrm{O}$ arenito Vila Velha situa-se na base da Formação Campo Mourão e serve como um laboratório de campo, podendo ser considerado um análogo aflorante de reservatórios produtores de gás na parte profunda da bacia. Os resultados das análises estratigráfica e estrutural realizadas no presente trabalho demonstram que os reservatórios têm grande anisotropia e que não podem ser encarados como unidades arenosas homogêneas nos trabalhos de exploração e explotação.

Em termos de geometria externa, o arenito Vila Velha constitui um corpo com cerca de $100 \mathrm{~m}$ de espessura, com topo plano e base irregular, e extensão lateral mínima de $10 \mathrm{~km}$. Internamente, podem ser constatadas heterogeneidades estratigráficas 
(deposicionais) e estruturais que exercem influência nos caminhos de permeabilidade verticais e laterais. Essas heterogeneidades são imperceptíveis nos levantamentos de subsuperfície (sísmica convencional e perfis de poços) e só podem ser analisadas mediante levantamentos de alta resolução na faixa de afloramentos.

Os três intervalos arenosos mapeados na escala 1:25.000 (figura 3) representam unidades preferenciais de fluxo de fluidos e são limitadas por horizontes de baixa permeabilidade (baffles) ou camadas lamíticas impermeáveis de grande continuidade lateral (barreiras). As unidades $C$ e $D$ são mais homogêneas faciologicamente e apresentam permeabilidade horizontal mais efetiva em função da tabularidade dos estratos e pouca variação textural na lateral. A unidade $A$ é a mais heterogênea, pois as fácies distribuem-se em elementos arquiteturais de geometria canalizada ou lenticulares. As direções de permeabilidade devem estar fortemente controladas pela direção dos canais e por estratificação cruzada planar de grande porte. As melhores fáciesreservatório deverão ser prospectadas na parte superior da unidade $D$, na qual foram descritos arenitos bem selecionados e homogêneos depositados em ambiente costeiro de alta energia.

Somados à anisotropia estratigráfica, os eventos tectônicos superpostos compartimentaram as unidades mapeadas em blocos ou unidades de fluxos limitados por estruturas rúpteis marcadas por sistemas de fraturas e zonas de falha. Bandas de deformação de espessura centimétrica e fraturas subverticais constituem as principais feições estruturais que controlam os caminhos de permeabilidade vertical e podem ter atuado tanto como barreira quanto conduto na circulação de fluidos durante o tempo geológico.

As estruturas rúpteis observadas apresentam evidências de deformação inter e intragranular descritas em trabalhos de análise microestrutural (Trzaskos-Lipski \& Rostirolla 2005) e podem exibir características de cisalhamento localizado ou desenvolvimento de fraturas de tração. As microestruturas formadas variam com as direções dos planos das falhas, sugerindo comportamento hidráulico distinto entre os sistemas de fraturas.

As bandas de deformação marcadas pelo desenvolvimento de fraturas de tração apresentam preenchimento atual por hidróxidos de ferro, o que evidencia que essas zonas de cisalhamento foram mais propensas à circulação de fluidos quando ativas. Bandas de deformação marcadas pela cominuição intensa dos grãos e com formação de uma zona brechada e/ou zona gouge apresentam redução na permeabilidade, sugerindo que esse sistema atuou como barreira hidráulica à migração de fluxo após sua nucleação.

\section{CONCLUSÕES}

Além de fornecer subsídios para a compreensão da evolução tectônica da porção inferior do Grupo Itararé, o arenito Vila Velha ofereceu a oportunidade de analisar heterogeneidades deposicionais e estruturais presentes em reservatórios análogos do Sistema Petrolífero Ponta Grossa - Itararé. A análise estrutural, com suporte de um arcabouço estratigráfico de alta resolução e de mapeamento geológico de detalhe, permitiu identificar diferentes estágios da evolução tectônica da área e determinar, grosso modo, a cronologia desses eventos que afetaram o arenito Vila Velha.

$\mathrm{Na}$ área estudada, o Grupo Itararé foi depositado sobre um substrato constituído por rochas devonianas afetadas por tectonismo relacionado à Orogenia EoHerciniana (Eo a Meso-Carbonífero). Evidências desse evento são o hiato de tempo envolvido na discordância pré-Pensilvaniano, o basculamento generalizado do substrato pré-Itararé e a movimentação ao longo de falhas nordeste, tais como a Falha da Fortaleza. Os dados obtidos indicam que essa instabilidade tectônica pode ter se prolongado até o Carbonífero Superior, com a Falha da Fortaleza controlando a deposição e a erosão subseqüente dos diamictitos da Formação Lagoa Azul.

Após a deposição do arenito Vila Velha em contexto essencialmente glácio-marinho, suas rochas foram submetidas a vários eventos deformacionais rúpteis durante o intervalo Permiano-Terciário. O primeiro evento, possivelmente relacionado à orogenia La Ventana no extremo sul da Placa Sulamericana durante o Permiano, foi responsável pela geração e reativação de estruturas NNE e NE, segundo cinemática transcorrente sinistral. O segundo evento é marcado por intenso fraturamento NW e geração de falhas de pequeno rejeito, sendo vinculado ao soerguimento do Arco de Ponta Grossa no Eocretáceo. Sugere-se que um terceiro evento de idade cenozóica possa ter atuado na área, com a reativação da Falha da Fortaleza (N40E) segundo cinemática normal e estabelecimento da configuração morfoestrutural atual do arenito.

A natureza da sedimentação e a deformação tectônica superimposta em múltiplos eventos imprimiram ao arenito intensa anisotropia, com diferentes escalas de heterogeneidades estruturais e estratigráficas ${ }_{\perp}$ que limitam unidades de fluxo e controlam a circulação de fluidos no meio poroso. 


\section{AGRADECIMENTOS}

Os autores externam seus agradecimentos à Universidade Federal do Paraná, pelo apoio institucional, à Petrobras e à Finep, pelo suporte financeiro e à Capes, pela concessão de bolsa de doutorado à primeira autora. Agradecem também aos relatores do Boletim Paranaense de Geociências pelas sugestões e críticas. Sidnei P. Rostirolla agradece ao CNPq pela concessão de bolsa de produtividade em pesquisa (processo 350905/99-1).

\section{REFERÊNCIAS}

ASSINE M. L. 1996. Aspectos da estratigrafia das seqüências pré-carboníferas da Bacia do Paraná no Brasil. Instituto de Geociências, Universidade de São Paulo, São Paulo, Tese de Doutorado, 207 p.

AYDIN A. 1978. Small faults formed as deformation bands in sandstones. Pure and Applied Geophysics, 116:913-930.

FERREIRA F. J. F. 1982. Alinhamentos estruturais magnéticos da região centro-oriental da Bacia do Paraná e seu significado tectônico. Relatório Pauli Petro, Consórcio Cesp/IPT Reavaliação da Potencialidade e Prospectividade em Hidrocarbonetos, 143-166.

FRANÇA A. B. \& POTTER P. E. 1988. Estratigrafia, ambiente deposicional e análise de reservatório do Grupo Itararé (Permocarbonífero), Bacia do Paraná (parte 1). Boletim de Geociências da Petrobrás, 2:147-191.

FRANÇA A. B. \& POTTER P.E. 1991. Stratigraphy and reservoir potential of glacial deposits of the Itararé Group (Carboniferous-Permian), Paraná Basin, Brasil. American Association of Petroleum Geologists Bulletin, 75:62-85.

FRANÇA A. B., WINTER W. R., ASSINE M. L. 1996. Arenitos Lapa-Vila Velha: um modelo de trato de sistemas subaquosos canal-lobos sob influência glacial, Grupo Itararé (C-P), Bacia do Paraná. Revista Brasileira de Geociências, 26(1):43-56.

LÓPEZ-GAMUNDí O. \& ROSSELLO E. A. 1993. DevonianCarboniferous unconformity in Argentina and its relation to Eo-Hercynian orogeny in southern South America. Geologische Rundschau, 82:136-147.

MAACK R. A. 1946. Geologia e geografia da região de Vila Velha (Paraná) e considerações sobre a glaciação carbonífera no Brasil. Arquivos do Museu Paranaense 5:1305.

MILANI E. J. 1997. Evolução tectono-estratigráfica da Bacia do Paraná e seu relacionamento com a geodinâmica Fanerozóica do Gondwana sul-ocidental. Universidade Federal do Rio Grande do Sul, Porto Alegre, Tese de Doutorado, 2 v, 255 p.

RICCOMINI C., SANT'ANNA L. G., FERRARI A. L. 2004. Evolução geológica do rift continental do sudeste do Brasil. In: MANTESSO-NETO V., BARTORELLI A., CARNEIRO C. D. R., BRITO-NEVES B. B. Geologia do continente SulAmericano: evolução da obra de Fernando Flávio Marques de Almeida, São Paulo, Beca, 383-406.
RICCOMINI C., ALMEIDA R. P., TURRA A., CHAMANI M. A. C., FAIRCHILD T. R.; HACHIRO J. 2005. Reativação de falha do embasamento cristalino causa sismicidade no Permotriássico da Bacia do Paraná. Curitiba - PR. In: Anais do X Simpósio Nacional de Estudos Tectônicos, Boletim de Resumos Expandidos, 18-20.

ROSTIROLLA S. P., ASSINE M. L., FERNANDES L. A., ARTUR P. C. 2000. Reativação de paleolineamentos durante a evolução da Bacia do Paraná - o exemplo do Alto Estrutural de Quatiguá. Revista Brasileira de Geociências, 30(4):639648.

ROSTIROLLA S. P., APPI C. J., MANCINI F., KRAFT R. P., BARTOSZECK M. K. 2002. Fraturas controladoras da migração de fluidos nos Arenitos Vila Velha, Grupo Itararé, Bacia do Paraná. Revista Brasileira de Geociências, 31:349356.

ROSTIROLLA S. P., MANCINI F., RIGOTI A., KRAFT R. P. 2003. Structural styles of the intracratonic reactivation of the Perimbó fault zone, Paraná basin, Brazil. Journal of South American Earth Sciences, 16:287-300.

SCHNEIDER R. L., MUHLMANN H., TOMMASI E., MEDEIROS R. A., DAEMON R. A., NOGUEIRA A. A. 1974. Revisão estratigráfica da Bacia do Paraná. In: SBG, 28 Congresso Brasileiro de Geologia, Porto Alegre, Anais... 1:41-65.

SOARES P. C. 1991. Tectônica sinsedimentar cíclica na Bacia do Paraná: controles. Tese para concurso ao cargo de professor titular da Universidade Federal do Paraná, Departamento de Geologia, $148 \mathrm{p}$.

SOARES P. C., ROSTIROLLA S. P., FERREIRA F. J. F., STEVANATO R. 1996. O alto estrutural Pitanga-QuatiguáJacutinga na Bacia do Paraná: uma estrutura litosférica. In: Cong. Brás. Geol., 39, Salvador, 1996. Anais... 5:411-414.

TANKARD A. J., ULIANA M. A., WELSINK H. J., RAMOS V. A., TURIC M., FRANÇA A. B., MILANI E. J., BRITO NEVES B. B., EYLES N., SANTA ANA H., WIENS E., CIRBIAN M., LÓPEZ PAULSEN O., GERMS G. J. B., DE WIT M. J., MACHACHA T; MILLER R. M. 1996. Tectonic controls of basin evolution in southwestern Gondwana. AAPG Memoir 62, 5-52.

TRZASKOS-LIPSKI B., ROSTIROLLA S. P., VESELY F. F., BOCARDI L. B., MANCINI F., APPI C. J. 2003. Microtectônica e sua importância no estudo da circulação de fluidos em reservatórios fraturados do Grupo Itararé - Bacia do Paraná. Búzios - RJ. In: Simpósio Nacional de Estudos Tectônicos, 9, Boletim de Resumos Expandidos, Anais... 361. 
TRZASKOS-LIPSKI B. \& ROSTIROLLA S. P. 2005. Microtectônica de bandas de deformação em arenitos permocarboníferos da Bacia do Paraná. Curitiba - PR. In: Simpósio Nacional de Estudos Tectônicos, 10, Boletim de Resumos Expandidos, Anais... 523-525.

VESELY F. F. \& ASSINE M. L. 2004. Seqüências e tratos de sistemas deposicionais do Grupo Itararé, norte do Estado do Paraná. Revista Brasileira de Geociências, 34:219-230.

VESELY F. F., TRZASKOS-LIPSKI B., KRAFT R. P., ROSTIROLLA S. P., APPI C. J. 2003a. Facies architecture of a Permocarboniferous sandstone reservoir analogue, Itararé Group, Paraná Basin, Brazil. In: Latin American Congress of Sedimentology, 3, Anais...
VESELY F. F., TRZASKOS-LIPSKI B., ROSTIROLLA S. P., APPI C. J., FIGUEIRA I. F. R. 2003b. Aspectos da evolução tectonosedimentar do Grupo Itararé no sudeste do Estado do Paraná. Búzios - Rj. In: Simpósio Nacional de Estudos Tectônicos, Boletim de Resumos Expandidos, Anais... 349352.

VIEIRA A. J. 1973. Geologia do centro e nordeste do Paraná e centro-sul de São Paulo. In: Congresso Brasileiro de Geologia, 27, Aracaju - SE, Anais... 3:259-277.

ZALÁN P.V., WOLFF S., CONCEIÇÃO J. C. J., ASTOLFI M. A. M.; VIEIRA I. S., APPI V.T., ZANOTTO, O. A. 1987. Tectônica e sedimentação da Bacia do Paraná. Curitiba - PR. In: Simpósio Sul-Brasileiro de Geologia, 3, Atas... 1:441-477. 